\title{
FAKTOR-FAKTOR PENENTU PENGAMBILAN KEPUTUSAN PEMILIHAN MAYOR MAHASISWA S1 TAHUN AKADEMIK 2005/2006
}

\author{
(Determinant Factors of IPB Undergraduate \\ Students for Decision Making in Selecting Major Study Program) \\ Megawati Simanjuntak ${ }^{1}$ dan Irni Rahmayani Johan ${ }^{2}$
}

\begin{abstract}
In determining major choosing, students as consumers were influenced by internal and external factors. The aimed of this research was to study the determinant factors in decision making of undergraduate students academic year 2005/2006. The research was conducted in Bogor Agricultural University (IPB) Dramaga, Bogor since May to November 2006 by using one time cross sectional study. Sampling technique used was stratified random sampling with 331 samples. Data were collected by using questionnaire as a guide. Most of samples had determined their major since they entered IPB. Alumni job prospect was the first information they looked when read major's information. For most samples, open house and promotion activities in Graduate Square influenced their major decision making. In addition, self interest (66.6\%) and alumni job prospect (53.2\%) influenced major decision making. This time, most samples (61.9\%) had first major choosing and according to them the major suited their desire (74.0\%). Logistic regression showed that samples with cumulative grade index $\geq 2.75$ had opportunity 3.5 times to obtain major suited to their desire compare with samples with cumulative grade index $<$ 2.75. Major determine based on self interest had opportunity 1.467 times to obtain major suit to their desire compare with samples not based on self interest. The active seeking information samples had opportunity 1.489 times to obtain major suited their desire compare with passive seeking information samples.
\end{abstract}

Key Words: Decision Making, Major Choosing, Undergraduate Students

\section{PENDAHULUAN}

Latar Belakang

Untuk mewujudkan visi dan misinya, IPB melakukan perubahan baik secara kelembagaan maupun dalam penyeleng- garaan sistem pendidikan. Salah satu perubahan dalam penyelenggaraan sistem pendidikan IPB adalah akan diterapkannya sistem mayor minor secara efektif pada tahun ajaran 2005/2006. Kurikulum mayor minor merupakan sistem kurikulum berbasis kompetensi yang dilaksanakan oleh departemen, yang dapat memberikan keleluasaan dalam meramu mata ajaran untuk memperluas wawasan dan meningkatkan penyelenggaraan, serta dapat meningkatkan mutu dan relevansi program pendidikan (Chozin 2005).

Sistem mayor minor yang akan mulai diterapkan pada mahasiswa tahun akademik 2005/2006 berdasarkan SK Rektor
No:001/K13/PP/2005 diperkirakan akan memiliki implikasi terutama terhadap mahasiswa dan departemen yang menaungi mayor. Departemendepartemen yang telah lama berdiri maupun yang baru didirikan menghadapi tantangan agar menjadi pilihan utama mahasiswa TPB. Mahasiswa TPB juga dihadapkan pada banyaknya pilihan mayor yang menawarkan keunggulan dan kompetensi khusus sehingga dapat menimbulkan kebingungan di kalangan mahasiswa. Sebaliknya, sistem mayor akan menyebabkan adanya kecenderungan mahasiswa untuk berkompetisi agar dapat diterima di salah satu mayor yang diinginkannya.

Penerapan sistem mayor minor yang dilaksanakan pada tahun 2006 membuat departemen-departemen yang menyeleng- garakan program mayor untuk S1 memiliki tugas yang berat untuk mempromosikan diri kepada mahasiswa TPB agar 
mayornya menjadi pilihan utama. Meskipun pimpinan IPB menyatakan bahwa 34 departemen yang ada akan mendapatkan mahasiswa dan menjamin terdistribusinya mahasiswa ke dalam departemen secara merata, namun persaingan untuk mendapatkan mahasiswa yang berkualitas tidak dipungkiri akan terjadi. Tantangan terbesar dirasakan oleh departemendepartemen yang baru berdiri, dimana banyak mahasiswa TPB yang belum mengenal departemen-departemen tersebut. Berbagai upaya telah dilakukan 34 departemen di IPB dalam rangka mempromosikan dirinya.

Kegiatan promosi sebagai media informasi merupakan salah satu faktor yang menentukan apakah sebuah mayor akan dipilih oleh mahasiswa atau tidak. Banyak faktor lain yang mempengaruhi proses pengambilan keputusan individu. Pertukaran informasi dapat menjadi stimulus dalam pengenalan masalah, sehingga merupakan faktor penting yang akan mempengaruhi proses pengambilan keputusan (Kotler 1992; Engel, Blackwell, \& Miniard 1992).

Berdasarkan uraian di atas, maka peneliti tertarik untuk mengetahui sejauh mana pengaruh karakteristik sosial ekonomi, motivasi, peer group, informasi maupun indeks prestasi mahasiswa saat TPB berpengaruh terhadap pengambilan keputusan pemilihan mayor. Informasi ini akan sangat berguna bagi 34 mayor di IPB untuk melakukan kegiatan promosi kepada mahasiswa TPB angkatan selanjutnya.

\section{Tujuan Penelitian}

Tujuan penelitian ini adalah untuk mengkaji faktor-faktor penentu pengambilan keputusan pemilihan mayor mahasiswa S1 IPB tahun akademik 2005/2006 yang mencakup karakteristik sosial ekonomi, IPK, motivasi, peer group dan media informasi serta pengaruhnya terhadap kesesuaian pilihan mayor.
METODE PENELITIAN

Lokasi dan Waktu Penelitian

Penelitian dilaksanakan di Kampus IPB Dramaga, Bogor. Penelitian ini berlangsung selama 6 bulan, mulai bulan Mei hingga November 2006.

\section{Metode Penelitian}

Disain penelitian ini menggunakan one time cross sectional study dimana penelitian dilakukan hanya pada satu waktu tertentu (single period in time). Populasi penelitian ini adalah 2806 mahasiswa $\mathrm{S} 1$ tahun akademik 2005/2006 (angkatan 42) yang memilih 34 mayor yang ada di IPB.

Contoh penelitian dihitung menggunakan formula Slovin (1960) diacu dalam Guilford, J.P. and B. Fruchter (1973) sebagai berikut :

$$
\begin{aligned}
& n=\frac{N}{1+N e^{2}} \\
& \mathrm{~N}=\text { populasi penelitian } \\
& \mathrm{n}=\text { contoh penelitian } \\
& \mathrm{e}=\text { margin error }(0,05)
\end{aligned}
$$

Dengan menggunakan rumus di atas dan margin error 0,05 didapatkan jumlah contoh sebagai berikut :

$$
n=\frac{2806}{1+2806(0,05)^{2}}=350 \text { orang }
$$

Penentuan contoh dilakukan secara stratified random sampling dimana 34 mayor yang ada akan menjadi lapis. Selanjutnya untuk mewakili setiap mayor akan diambil 1011 contoh mahasiswa secara acak (random sampling). Namun setelah dilakukan pengumpulan data, karena masalah kelengkapan data, hanya 331 contoh yang dapat diolah.

$\begin{array}{cr}\text { Pengumpulan data dilakukan } \\ \text { engan metode survei } & \text { dengan } \\ \text { membagikan kuesioner kepada }\end{array}$
mahasiwa (Nazir 1999). Data yang dikumpulkan mencakup data primer dan sekunder. Data primer meliputi karakteristik sosial ekonomi contoh dan keluarga, peer group, media informasi, 
IPK mahasiswa saat TPB dan pilihan major serta kesesuaian pilihan mayor dengan kenyataan. Data karakteristik sosial ekonomi contoh dan keluarganya meliputi : (1) tingkat pendidikan dan pekerjaan orang tua (ayah-ibu), (2) pendapatan keluarga, (3) besar keluarga, (4) uang saku, (5) jenis kelamin; dan (6) kepribadian contoh.

Data sekunder yang mencakup data hasil pilihan mayor mahasiswa TPB 2005/2006 pada putaran pertama (semester ganjil) dan putaran kedua (semester genap) diperoleh melalui Direktorat TPB-IPB.

\section{Analisis Data}

Data yang diperoleh akan diolah dan disajikan dalam bentuk tabulasi frekuensi untuk data nominal dan ordinal. Data rasio dianalisis secara deskriptif (rata-rata, kisaran, standar deviasi). logistik. Untuk menganalisis faktor-faktor yang menentukan pilihan mayor sesuai dengan kenginan atau tidak digunakan multiple logistic regression analysis (Hosmer dan Lemeshow 2000). Analisis dilakukan dengan menggunakan software SPSS.

\section{HASIL DAN PEMBAHASAN}

Karakteristik Sosial Ekonomi Keluarga dan Contoh

Karakteristik Keluarga. Tingkat pendidikan bapak contoh sebagian besar adalah sarjana dari S0 hingga S3 yakni $42.0 \%$. Sementara itu, ibu contoh sebagian besar $(46.5 \%)$ adalah lulusan SLTA yang diikuti oleh pendidikan sarjana sebanyak $26.9 \%$. Sekitar $35 \%$ bapak contoh berprofesi sebagai PNS, sedangkan sisanya sebagian besar bekerja sebagai pedagang/wiraswasta
$(27.2 \%)$ dan karyawan swasta (24.2\%). Hanya sebagian kecil bapak contoh yang bekerja sebagai buruh, pensiunan dan petani. Sementara itu, ibu contoh lebih dari setengah $(55.6 \%)$ merupakan ibu rumah tangga yang diikuti dengan profesi sebagai PNS (39.9\%). Rata-rata besar keluarga contoh adalah 4.6 orang dan $49 \%$ doiantaranya termasuk keluarga kecil 2 sampai 4 orang.. Ratarata pendapatan keluarga contoh adalah $\mathrm{Rp} 450,487.94 /$ kapita/bulan. Persentase terba- nyak (44.7\%) pendapatan keluarga contoh berada pada kisaran $R p \geq \operatorname{Rp~250,000.00~-~}$ $<$ Rp 500,000.00.

Karakteristik Contoh. Sebagian besar contoh adalah perempuan $(65.6 \%)$. Rata-rata besar uang saku yang diperoleh contoh setiap bulannya adalah Rp 441,480.26 dengan persentase terbesar (51.7\%) masuk kategori $\geq \operatorname{Rp~250,000.00~hingga~}$ < Rp 500,000.00. Sebagian besar contoh termasuk kategori kepribadian ekstrovet (63.2\%) dan sisanya berkepribadian introvet (36.8\%).

Rata-rata indeks prestasi (IP) contoh penelitian adalah 2.98 yang sedikit lebih tinggi bila dibandingkan dengan indeks prestasi kumulatif (IPK) TPB 2005/2006 (2.92) (Tabel 1). Baik indeks prestasi contoh penelitian maupun populasi mahasiswa TPB 2005/2006 sebagian besar termasuk kategori sangat memuaskan yakni IP antara 2.75 hingga kurang dari 3.75 . Indeks prestasi mahasiswa TPB 2005/2006 pada saat pemilihan mayor putaran pertama yakni semester ganjil adalah paling rendah dibandingkan IPK contoh dan IPK TPB serta masih ada $6.3 \%$ mahasiswa yang mempunyai IP kurang dari 2.00 .

Tabel 1. Sebaran Contoh berdasarkan Indeks Prestasi (IP)

\begin{tabular}{|c|c|c|c|c|c|c|c|}
\hline \multirow{2}{*}{ No } & \multirow{2}{*}{ Kategori IP } & \multicolumn{2}{|c|}{ IPK Contoh } & \multicolumn{2}{|c|}{ IP Semester Ganjil TPB } & \multicolumn{2}{|c|}{ IPK TPB } \\
\hline & & $\mathrm{n}$ & $\%$ & $\mathrm{n}$ & $\%$ & $\mathrm{n}$ & $\%$ \\
\hline 1 & $\mathrm{IP}<2.00$ & 0 & 0.0 & 170 & 6.3 & 0 & 0.0 \\
\hline 2 & $2.00 \leq \mathrm{IP}<2.75$ & 95 & 28.7 & 984 & 36.3 & 965 & 35.9 \\
\hline 3 & $2.75 \leq \mathrm{IP}<3.75$ & 190 & 57.4 & 1234 & 45.5 & 1405 & 52.2 \\
\hline 4 & $\mathrm{IP} \geq 3.75$ & 46 & 13.9 & 324 & 11.9 & 319 & 11.9 \\
\hline \multicolumn{2}{|c|}{ Jumlah } & 331 & 100.0 & 2712 & 100.0 & 2689 & 100.0 \\
\hline & ata-Rata \pm SD & \multicolumn{2}{|c|}{$2.98 \pm 0.43$} & \multicolumn{2}{|c|}{$2.68 \pm 0.23$} & \multicolumn{2}{|c|}{$2.92 \pm 0.46$} \\
\hline
\end{tabular}

Vol. 1 No. 1/Januari 2008 - 99 
Motivasi

Lebih dari setengah $(60.1 \%)$ contoh menyatakan bahwa motivasi yang mendasari mereka dalam memilih mayor adalah kemampuan atau minat pribadi (Tabel 2). Dalam melakukan pemilihan mayor, sebanyak $64.4 \%$ contoh menyatakan bahwa sejak awal masuk IPB sudah menetapkan pilihannya. Pilihan tersebut dapat mengalami perubahan dengan masuknya informasi mayor-mayor lainnya melalui kegiatan promosi. Hal yang menarik adalah lebih dari $70 \%$ contoh menetapkan mayor sesuai keinginan sendiri, tanpa dipengaruhi oleh orang lain.

Tabel 2. Sebaran Contoh berdasarkan Motivasi dalam Memilih Mayor (jawaban bisa lebih dari 1) ( $n=331)$

\begin{tabular}{|l|l|r|r|}
\hline No & \multicolumn{1}{|c|}{ Motivasi memilih mayor } & \multicolumn{1}{|c|}{ Jumlah (n) } & \multicolumn{1}{c|}{ Persentase (\%) } \\
\hline 1 & Sesuai kemampuan/minat & 199 & 60.1 \\
\hline 2 & Tertarik dengan bidang yang ditawarkan & 98 & 29.6 \\
\hline 3 & Didorong orang tua & 39 & 11.8 \\
\hline 4 & Siap Kerja/Prospek & 40 & 12.1 \\
\hline 5 & Lain-Lain* & 14 & 4.2 \\
\hline
\end{tabular}

Ket : * beasiswa, cita-cita, coba-coba, didorong pemda dan guru,didorong kakak, kemauan keluarga, mencukupi syarat, sebuah taktik, tidak tahu, terpaksa

Model tradisional pembuatan keputusan konsumen menggambarkan proses keputusan pembelian dengan pendekatan pemecahan masalah secara logis, melalui lima tahapan mulai dari pengenalan masalah, pencarian informasi, evaluasi alternatif, pilihan dan evaluasi hasil. Tahapan pengambilan keputusan diklasifikasikan sebagai pendekatan pengambilan keputusan secara rasional. Pendekatan keputusan rasional konsumen adalah penaksiran dan evaluasi manfaat atau fungsi atribut produk untuk memenuhi keputusan yang memuaskan (Solomon 2002).

\section{Proses Pengambilan Keputusan Pemilihan Mayor \\ Pencarian informasi. Setelah} konsumen mengenali kebutuhan dan tergerak oleh stimuli, maka tahapan selanjutnya adalah pencarian informasi. Seberapa besar pencarian yang dilakukan oleh seseorang tergantung pada kekuatan dorongannya, jumlah informasi yang dimiliki, kemudahan memperoleh informasi tambahan, nilai yang diberikan pada informasi tambahan dan kepuasan yang diperoleh dari pencarian tersebut. Pada tahap ini konsumen mencari informasi yang disimpan dalam ingatan (pencarian internal) atau mendapatkan informasi yang relevan dengan keputusan dari lingkungan (Engel et al. 1992)

Sekitar $66 \%$ contoh melakukan pencarian informasi tentang mayor secara aktif. Sementara itu, hanya $46.5 \%$ contoh yang selalu menghadiri kegiatan promosi departemen. Terkait dengan radio sebagai salah satu media promosi, ternyata hanya $24.2 \%$ contoh yang pernah mendengar informasi mayor melalui media tersebut. Kebanyakan contoh yakni $63.1 \%$ memanfaatkan website untuk mengenali mayor yang ada di IPB. Hal ini dapat menjadi pertimbangan mayor untuk lebih memanfaatkan keberadaan media ini untuk memperkenalkan mayornya kepada mahasiswa dan masyarakat secara umum. Sedangkan bimbingan konseling hanya menjadi media memperoleh informasi mayor bagi $36.6 \%$ contoh. Informasi tentang mayor dari kakak kelas diperoleh lebih dari setengah contoh (57.4\%). Kesempatan untuk mendatangi 
departemen secara khusus untuk lebih mengenali mayor hanya dilakukan oleh $11.2 \%$ contoh. Hal tersebut biasanya dilakukan oleh contoh yang sudah memiliki ketertarikan terhadap mayor tertentu.

Erasmus, Boshoff dan Rousseau (2001) dan Harris (1998) menyatakan bahwa dalam proses pengambilan keputusan konsumen dapat dididik atau ditingkatkan perilakunya melalui implementasi pencarian informasi yang dibutuhkan untuk membuat keputusan yang baik.

Prospek kerja lulusan ternyata adalah informasi yang paling pertama ingin dilihat oleh sebagian besar $(57.1 \%)$ contoh saat membaca informasi tentang mayor. Selanjutnya yang ingin diketahui adalah jenis mata kuliah apa saja yang ditawarkan mayor $(21.2 \%)$ dan IPK minimal untuk dapat masuk ke mayor tersebut (14.2\%).

Pada Tabel 3 terlihat bahwa promosi di Graha Widya Wisuda (GWW) dimana semua departemen berkumpul dan mempromosikannya mayornya dengan cara yang menarik dianggap oleh sebagian besar contoh paling mempengaruhi pengambilan keputusan pemilihan mayor. Media promosi kedua yang juga mempengaruhi pengambilan keputusan adalah open house di masing-masing departemen. Menurut Erasmus, Boshoff dan Rousseau (2001) pilihan tidak selalu tergantung pada alternatif tetapi tergantung pada kondisi yang khusus, spesifikasi produk dan situasi yang

Tabel 3. Sebaran Contoh berdasarkan Media Promosi yang Mempengaruhi Pengambilan Keputusan Pemilihan Mayor

\begin{tabular}{|l|r|r|r|r|r|}
\hline \multicolumn{1}{|c|}{ Media informasi } & \multicolumn{1}{c|}{ STM } & \multicolumn{1}{c|}{ TM } & \multicolumn{1}{c|}{ CM } & \multicolumn{1}{c|}{ M } & \multicolumn{1}{c|}{ SM } \\
\hline a. Koran Kampus & 23.2 & 38.4 & 30.7 & 6.5 & 1.2 \\
\hline b. Open house Departemen & 0.9 & 4.6 & 32.9 & 34.8 & 26.8 \\
\hline c. Promosi di GWW & 2.2 & 4.0 & 26.5 & 35.7 & 31.7 \\
\hline d. Pariwara IPB & 10.0 & 33.9 & 37.6 & 14.7 & 3.8 \\
\hline e. Bimbingan Konseling & 10.0 & 31.2 & 31.8 & 19.9 & 7.2 \\
\hline f. Social Gathering & 8.9 & 22.5 & 41.2 & 20.9 & 6.5 \\
\hline g. Website departemen & 5.0 & 22.0 & 37.0 & 26.1 & 9.9 \\
\hline h. Radio & 23.3 & 35.5 & 31.1 & 9.1 & 0.9 \\
\hline i. Buku panduan Mayor Minor & 0.0 & 0.0 & 0.0 & 0.3 & 0.0 \\
\hline
\end{tabular}

Ket : STM = Sangat Tidak Mempengaruhi; TM = Tidak Mempengaruhi ; CM = Cukup Mempengaruhi; $\mathrm{M}=$ Mempengaruhi; $\mathrm{SM}=$ Sangat Mempengaruhi

Perangkat informasi yang dianggap paling mempengaruhi sampai sangat mempengaruhi oleh sebagian besar contoh adalah booklet (55.3\%). Promosi merupakan variabel strategi pemasaran yang digunakan untuk memperkenalkan atau menginformasikan keberadaan produk maupun jasa kepada para konsumen. Secara berturut-turut sebanyak 33.2 dan $31.1 \%$ contoh menganggap media promosi mayor yang paling efektif adalah promosi GWW dan open house (Tabel $4)$.
Pencarian informasi memerlukan waktu dan uang. Ketika terlalu banyak informasi diperoleh, satu atau lebih masalah akan muncul, dinataranya : 1) menunda keputusan karena membutuhkan waktu untuk informasi ekstra, 2) kemampuan pengambilan keputusan menurun karena tidak dapat mengelola atau menilai informasi dengan baik, 3) menyeleksi informasi yang tersedia, 4) kecapaian mental terjadi, 5) kecapaian keputusan terjadi. Kuantitas informasi dapat diproses oleh pemikiran orang yang terbatas. Kalau 
informasi diseleksi secara sadar, proses akan bias terhadap bagian pertama dari informasi yang diterima, kemudian pikiran lelah dan mulai mengabaikan informasi berikut atau lupa akan informasi yang pertama (Harris 1998).

Tabel 4.

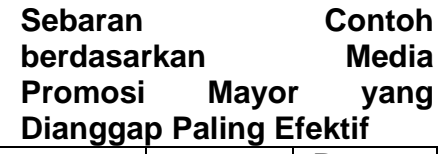

\begin{tabular}{|c|c|c|}
\hline Media Promosi & Jumlah & $\begin{array}{l}\text { Persen } \\
\text { tase }\end{array}$ \\
\hline Promosi GWW & 110 & 33.2 \\
\hline Open house & 103 & 31.1 \\
\hline Social Gathering & 32 & 9.7 \\
\hline Website & 13 & 3.9 \\
\hline Bimbingan Konseling & 7 & 2.1 \\
\hline Lain-lain* & 66 & 19.9 \\
\hline Jumlah & 331 & 100.0 \\
\hline $\begin{aligned} \text { Ket : } & \text { dialog interaktif, } \\
& \text { studium general, } \\
& \text { datang ke setia } \\
& \text { kelas, Pembimbi } \\
& \text { Asrama, SMS }\end{aligned}$ & $\begin{array}{l}\text { ara IPB, } \\
\text { isi, buletir } \\
\text { as TPB, i } \\
\text { kademik, s }\end{array}$ & $\begin{array}{l}\text { an, semina } \\
\text { ampus tou } \\
\text { dari kaka } \\
\text { ior Resider }\end{array}$ \\
\hline
\end{tabular}

Evaluasi Alternatif. Setiap keputusan menuntut penafsiran dan evaluasi terhadap informasi. Lazimnya data diterima dari berbagai sumber dan data itu perlu disaring, diproses dan ditafsirkan. Persepsi-persepsi dari pengambil keputusan akan menjawab pertanyaan ini. Alternatif-alternatif serta kekuatan dan kelemahan dari tiap alternatif perlu dievaluasi (Robbins 2001).

Sebagian besar (54.7\%) contoh menyatakan bahwa acara promosi mayor di GWW mempengaruhi dalam memilih mayor pada putaran kedua (Tabel 5). Hal ini sesuai dengan data pilihan pertama mahasiswa TPB antara putaran pertama dan kedua yang mengalami perubahan yang cukup signifikan untuk beberapa mayor. Sementara itu, mayor pilihan pertama pada putaran pertama sama dengan putaran kedua bagi $50.5 \%$ contoh.

Sebagian besar $(65.9 \%)$ contoh menyatakan bahwa pilihan mayor didasarkan pada besar nilai IPK, mempertimbangkan besar biaya SPP dan SKS yang harus bayar ketika memilih mayor (54.4\%), memilih mayor yang paling populer di kalangan teman $(74.3 \%)$, memilih mayor berdasarkan prospek kerja lulusan yang dijanjikan $(82.2 \%)$ dan berkonsultasi dengan keluarga tentang mayor yang harus dipilih (94.3\%).

Tabel 5. Sebaran Contoh berdasarkan Upaya Evaluasi Alternatif Proses Pengambilan Keputusan Mayor

\begin{tabular}{|c|c|c|c|c|}
\hline \multirow{2}{*}{ Pernyataan } & \multicolumn{2}{|c|}{ Ya } & \multicolumn{2}{|c|}{ Tidak } \\
\hline & $\mathrm{n}$ & $\%$ & $\mathrm{n}$ & $\%$ \\
\hline $\begin{array}{l}\text { a. Acara promosi mayor di GWW mempengaruhi dalam } \\
\text { memilih mayor pada putaran kedua }\end{array}$ & 150 & 45.3 & 181 & 54.7 \\
\hline $\begin{array}{l}\text { b. Mayor pilihan pertama pada putaran pertama sama } \\
\text { dengan putaran kedua }\end{array}$ & 164 & 49.5 & 167 & 50.5 \\
\hline c. Pilihan mayor didasarkan pada besar nilai IPK & 218 & 65.9 & 113 & 34.1 \\
\hline $\begin{array}{l}\text { d. Mempertimbangkan besar biaya SPP dan SKS yang } \\
\text { harus bayar ketika memilih mayor }\end{array}$ & 151 & 45.6 & 180 & 54.4 \\
\hline e. Memilih mayor yang paling populer di kalangan teman & 85 & 25.7 & 246 & 74.3 \\
\hline $\begin{array}{l}\text { f. Memilih mayor berdasarkan prospek kerja lulusan yang } \\
\text { dijanjikan }\end{array}$ & 272 & 82.2 & 59 & 17.8 \\
\hline $\begin{array}{l}\text { g. Berkonsultasi dengan keluarga tentang mayor yang } \\
\text { harus dipilih }\end{array}$ & 312 & 94.3 & 19 & 5.7 \\
\hline $\begin{array}{l}\text { h. Teman sekamar di asrama berpengaruh terhadap pilihan } \\
\text { mayor }\end{array}$ & 55 & 16.6 & 276 & 83.4 \\
\hline $\begin{array}{l}\text { i. Melakukan evaluasi terhadap pilihan-pilihan mayor yang } \\
\text { ada }\end{array}$ & 271 & 81.9 & 60 & 18.1 \\
\hline j. Mengalami kebingungan dalam menentukan mayor & 205 & 61.9 & 126 & 38.1 \\
\hline
\end{tabular}


Sebanyak 83.4\% contoh menyatakan bahwa teman sekamar di asrama berpengaruh terhadap pilihan mayor. Sebagian besar (61.9\%) contoh ternyata mengalami kebingungan dalam menentukan mayor yang akan dipilih. Hal ini sejalan pula dengan pernyataan Chozin (2007) bahwa hasil survey yang dilakukan terhadap calon mahasiswa IPB secara konsisten lebih dari $60 \%$ menyatakan sulit memebedakan satu program studi dengan yang lainnya. Selain itu, Erasmus, Boshoff dan Rousseau (2001) dan Harris (1998) menyatakan bahwa semakin banyak informasi semakin sulit keputusan dibuat.
Sebanyak $\quad 81.9 \% \quad$ contoh melakukan evaluasi terhadap pilihanpilihan mayor yang ada. Dalam menentukan mayor yang akan dipilih faktor-faktor yang sangat mempengaruhi bagi sebagian besar contoh adalah minat pribadi terhadap mayor $(66.6 \%)$ dan prospek kerja lulusan (53.2\%) (Tabel 6). Hal tersebut sejalan dengan pendapat mahasiswa yang menyatakan bahwa apabila mereka mencari informasi tentang mayor yang pertama dilihat dan ditanyakan adalah prospek kerja setelah lulus nantinya.

Tabel 6. Sebaran contoh berdasarkan faktor yang menentukan dalam pemilihan mayor $(n=331)$

\begin{tabular}{|l|r|r|r|r|r|}
\hline \multicolumn{1}{|c|}{ Faktor penentu } & STM & \multicolumn{1}{|c|}{ TM } & \multicolumn{1}{c|}{ CM } & \multicolumn{1}{c|}{ M } & SM \\
\hline a. Image/Popularitas mayor & 5.1 & 13.4 & $\mathbf{3 8 . 9}$ & 29.6 & 13.1 \\
\hline b. Prospek kerja lulusan mayor & 0.9 & 1.6 & 13.3 & 31.0 & $\mathbf{5 3 . 2}$ \\
\hline c. Mata kuliah yang menarik & 1.6 & 3.5 & 33.2 & $\mathbf{3 5 . 1}$ & 26.5 \\
\hline d. Minat pribadi terhadap mayor & 0.6 & 0.6 & 7.5 & 24.7 & $\mathbf{6 6 . 6}$ \\
\hline e. IPK & 0.9 & 3.5 & 23.3 & $\mathbf{4 3 . 7}$ & 28.6 \\
\hline f. Biaya SPP dan SKS & 3.5 & 14.0 & $\mathbf{3 6 . 5}$ & 28.9 & 17.1 \\
\hline g. Kualitas dosen & 1.9 & 6.3 & 34.6 & $\mathbf{4 0 . 3}$ & 16.8 \\
\hline h. Persyaratan mayor & 1.6 & 3.5 & 18.4 & $\mathbf{4 1 . 9}$ & 34.6 \\
\hline i. Keinginan Keluarga/Orang tua & 1.9 & 7.9 & 18.3 & $\mathbf{3 6 . 9}$ & 35.0 \\
\hline j. Rasio gender (mahasiswa laki-laki dan perempuan) & 24.5 & $\mathbf{4 3 . 0}$ & 20.2 & 11.3 & 1.0 \\
\hline
\end{tabular}

Menurut Solomon (2002) kelompok acuan yang mempengaruhi pembelian individu dapat berupa orangtua, kekasih, kelompok partai, teman, idola yaitu para selebritis. Faktor keluarga dianggap oleh sebagian besar $(55.2 \%)$ contoh sangat mempengaruhi. Sementara itu, teman asrama dan kakak kelas persentase terbesar contoh menilai cukup mempengaruhi. Menurut Schiffman dan Kanuk (2004) pengaruh pribadi dapat juga dikatakan sebagai pengaruh kelompok acuan yaitu orang atau kelompok orang yang memberi pengaruh secara bermakna pada individu baik secara umum maupun spesifik tentang nilai, sikap atau perilaku Dalam pemasaran, kelompok acuan sebagai pemberi pengaruh dalam pengambilan keputusan dalam membeli.

Pengambilan

Keputusan. Pengambilan keputusan adalah pemilihan suatu tindakan dari dua atau lebih pilihan alternatif (Schiffman \& Kanuk 1994). Sebagian besar (61.9\%) mayor contoh saat ini merupakan pilihan pertama (Gambar 1). Demikian pula bila dilihat data mahasiswa TPB secara keseluruhan, ternyata realisasi mayor sebagian besar (59.9\%) mahasiswa adalah hasil pilihan pertama. Sementara menurut Chozin (2007) dari evaluasi pemilihan mayor tahun 2006 sebenarnya 85\% mahasiswa mendapatkan mayor pada pilihan 1 sampai 5 , dan hanya sedikit yang mengajukan keberatan. Pada 
tahun berikutnya, jumlah mahasiswa yang berniat mengajukan kepindahan mayor hanya 12 mahaiswa saja. Bagaimanapun keluhan dari minoritas mahasiswa tersebut tetap dijadikan sebagai pertimbangan dalam menentukan kebijakan pemilihan mayor berikutnya. Data persentase yang diperoleh untuk keenam kategori peringkat pilihan mayor contoh penelitian tidak terlalu berbeda dengan persentase mahasiswa TPB.
Dalam perilaku konsumen, pengambilan keputusan yang dibuat tidaklah datang begitu saja tetapi berdasarkan pertimbanganpertimbangan tertentu sehingga keputusan terjadi. Menurut Engel et al (1992), terdapat beberapa fakor yang mempengaruhi proses pengambilan keputusan yaitu perbedaan individu, pengaruh lingkungan dan proses psikologis.

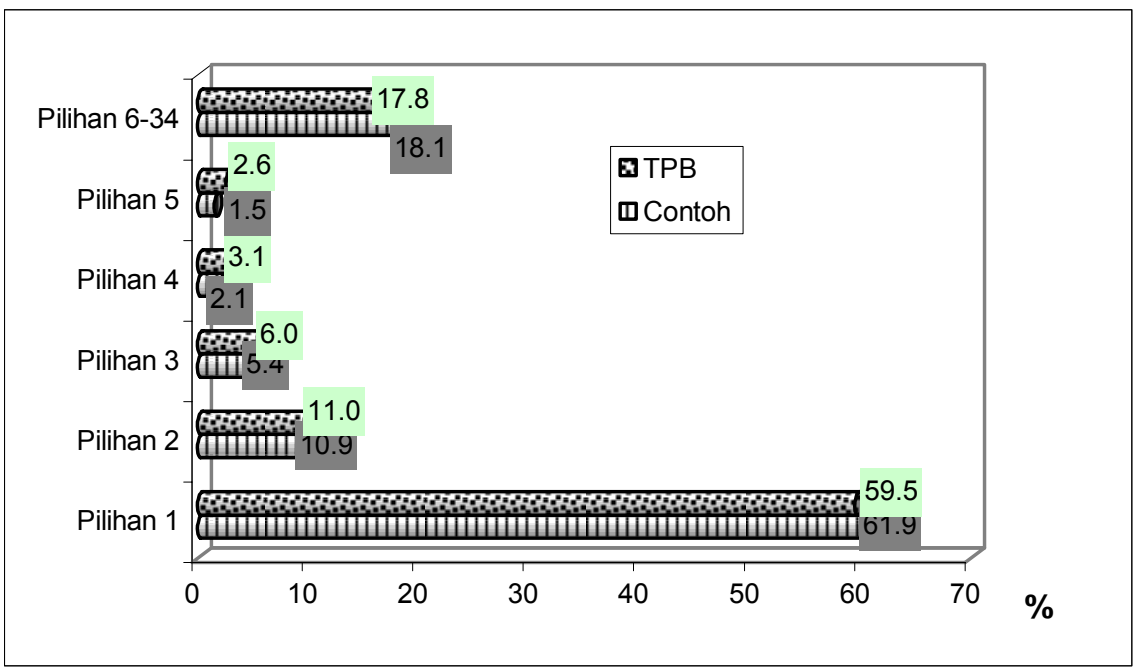

Gambar 1. Sebaran contoh berdasarkan pilihan mayor

Evaluasi Pasca Keputusan. Sebagian besar (74.0\%) contoh menyatakan bahwa mayor yang terealisasi saat ini adalah sesuai dengan keinginannya. Sisanya sebanyak $26.0 \%$ contoh menyatakan mayor yang saat ini dijalani tidak sesuai dengan yang diinginkan.

Pada Tabel 7 disajikan analisis regresi logistik faktor-faktor yang mempengaruhi kesesuaian mayor pilihan dengan yang diinginkan. Hasil analisis menunjukkan bahwa contoh yang mempunyai nilai IPK $\geq 2.75$ berpeluang 3.5 kali memperoleh mayor yang sesuai dengan keinginannya dibandingkan contoh dengan IPK di bawah 2.75. Penetapan mayor berdasarkan minat diri berpeluang 1.467 kali memperoleh mayor yang sesuai dengan keinginannya dibandingkan contoh dengan yang tidak mendasarkan pada minat diri. Contoh yang aktif mencari informasi berpeluang 1.489 kali memperoleh mayor yang sesuai dengan keinginannya dibandingkan contoh yang pasif mencari informasi. 
Tabel 7. Analisis regresi logistik faktor-faktor yang mempengaruhi kesesuaian mayor pilihan dengan yang diinginkan

\begin{tabular}{|l|c|c|c|r|}
\hline \multicolumn{1}{|c|}{ Peubah Independen } & B & Sig. & Interpretasi & Odd Ratio \\
\hline Indeks Prestasi Kumulatif & 1.251 & 0.000 & Nyata & 3.494 \\
\hline Penetapan pilihan mayor sebelum masuk IPB & 0.564 & 0.080 & Tidak Nyata & 1.758 \\
\hline Memilih mayor berdasarkan prospek kerja lulusan & -0.546 & 0.074 & Tidak Nyata & 0.580 \\
\hline Menetapkan mayor berdasarkan minat diri & 0.761 & 0.020 & Nyata & 1.467 \\
\hline Aktif mencari informasi mayor & 0.716 & 0.022 & Nyata & 1.489 \\
\hline Promosi GWW & -0.675 & 0.083 & Tidak Nyata & 0.509 \\
\hline Keluarga & -0.542 & 0.077 & Tidak Nyata & 0.582 \\
\hline Konstanta & 4.413 & 0.000 & & 82.544 \\
\hline
\end{tabular}

Sebanyak $\quad 17.2 \% \quad$ contoh menyatakan tidak puas terhadap mayor yang saat ini dijalani. Bila dikaitkan dengan peringkat pilihan mayor yang terealisasi, dapat dilihat bahwa persentase contoh yang pilihannya antara pilihan 6 hingga 34 juga tidak jauh berbeda yakni $18.1 \%$. Dengan demikian, dapat dikatakan bahwa umumnya ketidakpuasan terhadap mayor yang diperoleh berasal dari contoh yang pilihannya di atas peringkat 5. Hal ini dapat dipahami, karena adanya kekecewaan mahasiswa dengan hasil mayornya saat ini yang tidak sesuai dengan keinginannya atau bahkan jauh dari yantg diperkirakan.

\section{Evaluasi Sistem Mayor-Minor}

Sosialisasi sistem mayor-minor yang dilakukan pihak IPB dianggap oleh $73.4 \%$ contoh belum memadai (Tabel 8). Lebih dari 75\% contoh menyatakan bahwa prosedur mayor- minor sulit untuk dipahami. Sekitar $78 \%$ contoh menganggap penjelasan dan informasi dari IPB terkait prosedur pemilihan Mayor IPB 2005/2006 tidak memadai. Selanjutnya kegiatan promosi mayor yang dilakukan dikatakan oleh setengah contoh belum memberikan pemahaman tentang mayor. Sebanyak $85 \%$ contoh mengatakan agar promosi mayor dilakukan pada calon mahasiswa saat mereka masih di SMA. Sekitar 50\% contoh menyatakan agar pemilihan mayor dilakukan sebelum masuk IPB. Hal lain yang menarik untuk dicermati dan perlu memperoleh perhatian adalah waktu pencarian informasi tentang mayor yang masih dirasakan kurang oleh $65.3 \%$ contoh. Banyaknya kekurangan sistem mayor-minor pada tahun pertama penerapannya disebabkan oleh proses penataan departemen dan penyusunan kurikulum mayor-minor belum tuntas (Chozin 2007).

Tabel 8. Sebaran contoh berdasarkan evaluasi terhadap pelaksanaan mayor

\begin{tabular}{|l|r|r|r|r|}
\hline \multicolumn{1}{|c|}{ Pernyataan } & \multicolumn{2}{c|}{ Ya } & \multicolumn{2}{c|}{ Tidak } \\
\cline { 2 - 5 } & $\mathbf{n}$ & \multicolumn{1}{c|}{$\%$} & \multicolumn{1}{c|}{$\mathbf{n}$} & $\%$ \\
\hline a. Sosialisasi sistem mayor-minor sudah cukup memadai dari pihak IPB & 88 & 26.6 & 243 & 73.4 \\
\hline b. Prosedur mayor-minor sulit untuk dipahami & 254 & 76.7 & 77 & 23.3 \\
\hline c. Penjelasan dan informasi dari IPB terkait prosedur pemilihan Mayor IPB \\
$\begin{array}{l}\text { 2005/2006 sudah memadai } \\
\text { d. Kegiatan promosi mayor yang dilakukan telah memberikan pemahaman } \\
\text { tentang mayor }\end{array}$ & 72 & 21.8 & 259 & 78.2 \\
\hline e. Promosi mayor harus dilakukan pada calon mahasiswa saat mereka & 164 & 49.5 & 167 & 50.5 \\
\hline $\begin{array}{l}\text { masih di SMA } \\
\text { f. Lebih baik memilih mayor sebelum masuk IPB }\end{array}$ & 281 & 84.9 & 50 & 15.1 \\
\hline g. Waktu pencarian informasi tentang departemen sudah memadai & 163 & 49.2 & 168 & 50.8 \\
\hline
\end{tabular}

Vol. 1 No. 1/Januari 2008 - 105 
SIMPULAN DAN SARAN

\section{Simpulan}

a. Tingkat pendidikan bapak contoh sebagian besar adalah sarjana dari S0 hingga S3 yakni $42.0 \%$. Sementara itu, ibu contoh sebagian besar (46.5\%) adalah lulusan SLTA yang diikuti oleh pendidikan sarjana sebanyak $26.9 \%$. Sebagian besar contoh adalah berjenis kelamin perempuan (65.6\%). Rata-rata besar uang saku yang diperoleh contoh setiap bulannya adalah Rp $441.480,26$ dengan persentase terbesar $(51.7 \%)$ masuk kategori $\geq$ Rp 250.000 hingga < Rp 500.000. Rata-rata indeks prestasi contoh penelitian adalah 2.98 yang sedikit lebih tinggi bila dibandingkan dengan IPK TPB 2005/2006 (2.92) yang sebagian besar termasuk kategori sangat memuaskan yakni IP antara 2.75 hingga kurang dari 3.75 .

b. Motivasi terbesar $(60.1 \%)$ contoh dalam memilih mayor adalah kemampuan atau minat pribadi. Sebanyak $64.4 \%$ contoh sejak awal masuk IPB sudah menetapkan pilihannya.

c. Sekitar $66 \%$ contoh melakukan pencarian informasi tentang mayor secara aktif. Prospek kerja lulusan ternyata adalah informasi yang paling pertama ingin dilihat oleh sebagian besar $(57.1 \%)$ contoh saat membaca informasi tentang mayor.

d. promosi di Graha Widya Wisuda (GWW) dimana semua departemen berkumpul dan mempromosikannya mayornya dengan cara yang menarik dianggap oleh sebagian besar contoh paling mempengaruhi pengambilan keputusan pemilihan mayor. Media promosi kedua yang juga mempengaruhi pengambilan keputusan adalah open house di masing-masing departemen.

e. Sebagian besar (65.9\%) contoh menyatakan bahwa pilihan mayor didasarkan pada besar nilai IPK dan memilih mayor berdasarkan prospek kerja lulusan yang dijanjikan (82.2\%) dan berkonsultasi dengan keluarga tentang mayor yang harus dipilih $(94.3 \%)$.

f. Dalam menentukan mayor yang akan dipilih faktor-faktor yang sangat mempengaruhi bagi sebagian besar contoh adalah minat pribadi terhadap mayor $(66.6 \%)$ dan prospek kerja lulusan $(53.2 \%)$. Faktor keluarga dianggap oleh sebagian besar (55.2\%) contoh sangat mempengaruhi.

g. Sebagian besar $(61.9 \%)$ mayor contoh saat ini merupakan pilihan pertama. Sebagian besar $(74.0 \%)$ contoh menyatakan bahwa mayor yang terealisasi saat ini adalah sesuai dengan keinginannya.

h. Hasil analisis regresi logistik menunjukkan bahwa contoh yang mempunyai nilai IPK $\geq 2.75$ berpeluang 3.5 kali memperoleh mayor yang sesuai dengan keinginannya dibandingkan contoh dengan IPK di bawah 2.75. Penetapan mayor berdasarkan minat diri berpeluang 1.467 kali memperoleh mayor yang sesuai dengan keinginannya dibandingkan contoh dengan yang tidak mendasarkan pada minat diri. Contoh yang aktif mencari informasi berpeluang 1.489 kali memperoleh mayor yang sesuai dengan keinginannya dibandingkan contoh yang pasif mencari informasi.

i. Sebanyak $17.2 \% \quad$ contoh menyatakan tidak puas terhadap mayor yang saat ini dijalani karena adanya kekecewaan mahasiswa dengan hasil mayornya saat ini yang tidak sesuai dengan keinginannya atau bahkan jauh dari yang diperkirakan. 
Saran

a. Pelaksanaan mayor-minor perlu ditingkatkan dan disempurnakan secara terus menerus sehingga tingkat kepuasan mahasiswa terhadap sistem yang baru berjalan ini dapat meningkat

b. Sosialisasi sistem mayor-minor dan promosi mayor harus dilakukan sedini mungkin, bahkan langsung ke SLTA-SLTA

c. Peningkatan infrastruktur yang mendukung implementasi sistem mayor-minor harus terus ditingkatkan

d. Bagi mayor-mayor yang ada di IPB akan lebih baik melakukan promosi pada saat mahasiswa baru masuk serta secara kontinyu dan tidak melakukan promosi pada saat mahasiswa akan melakukan pemilihan mayor.

e. Kegiatan promosi dengan peserta setiap departemen lebih baik dipusatkan di satu tempat seperti GWW karena akan lebih efektif dibandingkan dilakukan di departemen masing-masing atau melalui media lainnya

\section{DAFTAR PUSTAKA}

Chozin MA. 2005. Sistem Penyenggaraan Akademik IPB. Makalah disajikan pada Prajabatan Angkatan 1, 2 dan 3 CPNS golongan III IPB. Sawangan, Bogor. 2007. Mengawal Otonomi : Menuju Perguruan Tinggi Pertanian Berbasis Riset. Bogor : IPB Press.

Erasmus, A.C., E. Boshoff, G.G. Rousseau. 2001. Consumer decision making models within the discipline of consumer science : A critical approach. Journal of Family Ecology and Consumer Sciences 29:82-90.

Harris, R. 1998. Introduction to Decision Making. Virtualsalt.

Hosmer, D.W., S. Lemeshow. 2000. Applied Logistic Regression. New York: A Wiley-Interscience Publication.

Kottler, P. 1992. Manajemen Pemasaran Analisis, Perencanaan dan Pengendalian. Jakarta: Erlangga.

Nazir, M. 1999. Metode Penelitian. Jakarta : Ghalia Indonesia.

Robbins, S.P. 2001. Organizational Behavior. New Jersey: Prentice-Hall.

Schiffman, L.G., L.L. Kanuk. 2004. Perilaku Konsumen. Edisi ketujuh. (Kasip Z, penerjemah). Jakarta: PT Indeks Kelompok Gramedia.

Solomon, M.R. 2002. Consumer Behavior. Buying, Having, and Being. Fifth Edition. New Jersey: Prentice-Hall International, Inc.

Guilford, J.P., B. Fruchter. 1973. Fundamental Statistics in Psychology and Education, 5th Edition. New York: Mc Graw-Hill.

1 Staf Pengajar Departemen IImu Keluarga dan Konsumen, FEMA IPB

2 Staf Pengajar Departemen IImu Keluarga dan Konsumen, FEMA IPB 